\title{
OPINION
}

\section{Mathematics support centres from a sociocultural point of view}

Kirsten Pfeiffer, School of Mathematics, Statistics and Applied Mathematics, NUI Galway, Ireland. Email: kirsten.pfeiffer@nuigalway.ie

\section{Abstract}

Mathematics support centres provide opportunities for students to work in groups or explore mathematics with some guidance, which is often difficult to achieve in large lectures or tutorials. In this article I discuss the role of mathematics support centres from a socio-cultural point of view. In this view learning takes place as participation in a community of practice. Providing access to such a community is seen as crucial for the transition from school to university, however it is particularly challenging to provide authentic opportunities for mathematical practice in a university environment. I argue that mathematics support centres have potential to provide such opportunities for students and are therefore significant for the progress of newcomers in the practice.

Keywords: Maths Support Centre, Community of Mathematical Practice, Learning as Participation in a Community of Practice

\section{Introduction}

Maths support centres support learning of mathematics at further and higher education institutions to complement lectures, tutorials, etc. In this role many maths support centres aim to provide friendly, informal environments where students of all mathematical levels of mathematical attainment can work, study and support each other, take control of their own learning and build confidence in their own mathematical ability.

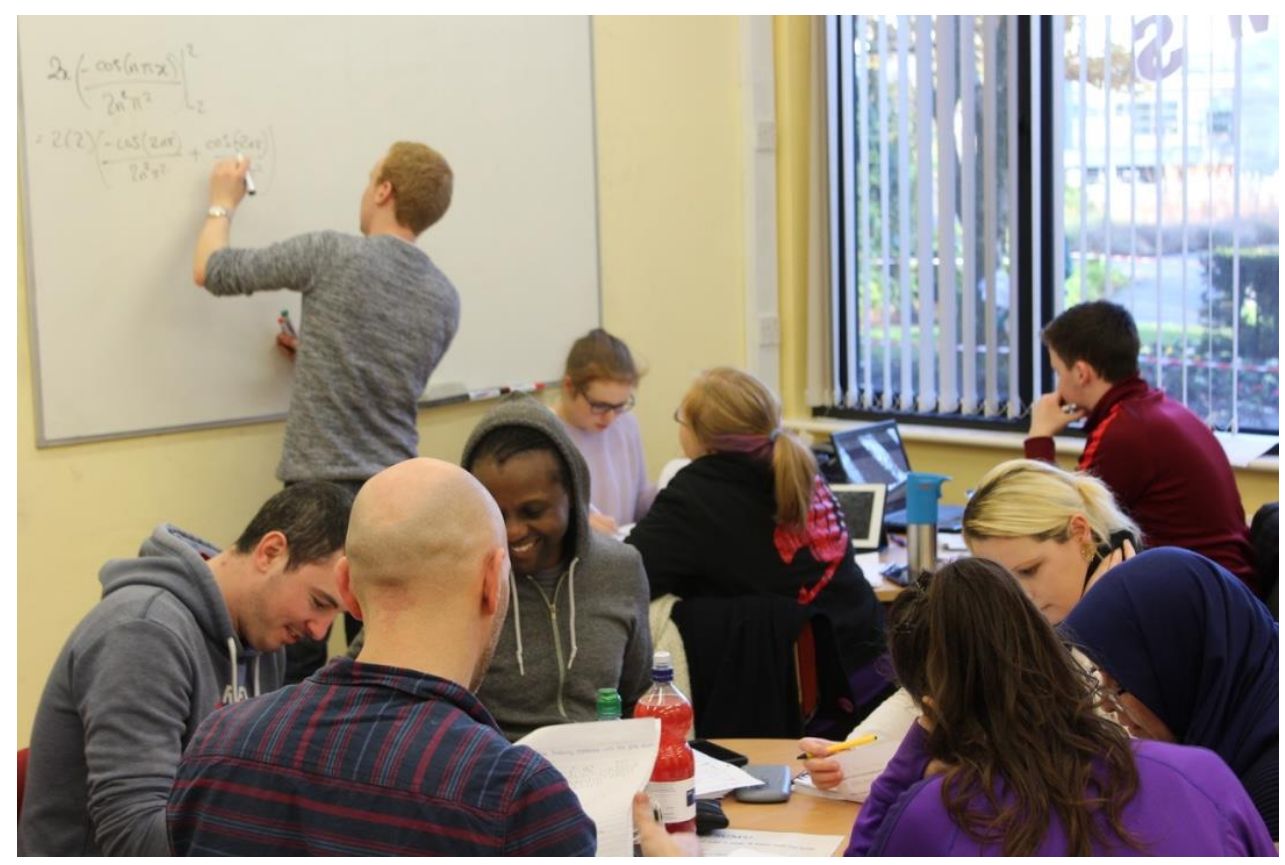

Figure 5. Students studying in the Maths Support Centre at NUI, Galway 
In this article I take a sociocultural view and argue that maths support centres particularly provide opportunities for students to participate in communities of mathematical practice and therefore play an important role for the development of mathematical identities.

The next section explains what is meant by community of mathematical practice, and how learning appears in such a community.

\section{Learning from a sociocultural perspective}

In the field of education research the view of learning has changed in the last 40 years: from mostly influenced by constructivist views concerned with the development of individual learners (e.g. Piaget or Bruner), to more sociocultural approaches to learning based on the work of Vygotsky (1986). A key feature of this view of human development is that learning develops out of social interaction. Vygotsky argues that a child's development cannot be understood by a study of the individual in isolation. The external social world in which that individual life has developed must also be examined. Vygotsky describes learning as being embedded within social events and occurring as a child interacts with people, objects, and events in the environment.

Influenced by Vygotsky's theories, Lave and Wenger established their theory of legitimate peripheral participation. This theory argues that knowledge is distributed amongst a community of practice, and can only be understood with the 'interpretive support' provided by participation in the community of practice itself.

I will now explain what Lave and Wenger mean by community of practice and how they interpret learning within this theory.

Wenger characterizes a community of practice by its three dimensions:

- Mutual engagement (engaged diversity, doing things together, relationships, social complexity, community, maintenance);

- Joint enterprise (negotiated enterprise, mutual accountability, interpretations, rhythms, local response);

- Shared repertoire (stories, styles, artefacts, tools, actions, historical events, discourses, concepts).

A community of practice is not static, it is changing continuously: over time, forms of participation and identities change as newcomers themselves become 'old-timers' with respect to the next set of newcomers.

In this view, learning is about becoming, about participating in practices. It occurs through participation in activities and contributes to a growing identity within or across communities of practice. Identity is built around social engagement and is constantly being renegotiated as individuals move through different forms of participation.

Lave and Wenger's examples of learning in communities of practice are mostly located in 'real world' work situations, for example a group of claim processors in an insurance company. Practices here are beside other common activities defined by the practical work the members share. Those communities of practice differ from communities at universities as these are mostly defined by common or shared knowledge of its members and some researchers refer to them as communities of knowledge. Communities at universities are complex, and interaction and tensions between 
different communities can cause difficulties for members to establish their own professional identities.

The role of maths support centres is to support learning of mathematics at universities, between a variety of communities of knowledge, and to invigorate students' development of mathematical identity and mathematical confidence. How does learning or development of identity appear in such a community?

\section{Learning in Communities of Mathematical Practice}

Kirsti Hemmi considers a maths department as community of mathematical practice. This community consists of "all people exercising and learning mathematics at the department of mathematics as members of a community of practice of mathematics. There are mathematicians, doctoral students, teaching assistants and students. It is a dynamic practice and the joint enterprise for all participants is the learning of mathematics in a broad sense".

Examples for each of the three dimensions in a community of mathematical practice may be

- Mutual engagement: studying, teaching, learning, communicating maths;

- Joint enterprise: learning and developing the practice;

- Shared repertoire: courses, words, symbols, concepts, proofs, artefacts, or computers.

In a mathematical practice learning or becoming knowledgeable includes for example learning to talk about mathematics, using its language and symbols, learning to prove, or validating mathematics.

Mathematics and its applications as well as statistics are taught and used in diverse ways at varied communities in a university: for example students of Engineering or Commerce may have different attitudes towards these subjects than a student of Mathematics. While the latter may aim to become a mathematics researcher, the others aim to become sufficient applicants of mathematical methods. I use the term 'Communities of Mathematical Practice' to include a mathematics department as described by Hemmi as well as the intersection of mathematical practice with other university communities.

To promote learning of mathematics and development of mathematical identities in a broad sense, teachers of mathematics need to encourage students to participate in these communities of mathematical practice. In particular they need to provide opportunities for students to participate in these communities. Considering the abstract nature of the topic and the relatively large size of many mathematics classes at universities, this seems to be quite a challenge.

Wenger claims that in a Community of Practice newcomers need to have "broad access to arenas of mature practice". "Mature practice"' at communities of mathematics practice include activities like mathematics research, communication with colleagues, participating at conferences, reading mathematical texts, or using mathematical methods to approach problems appearing in other fields such as industry or medicine.

However, typically students get to see mathematicians in lectures, where they might tell them about their work, and of course they see them teaching, but the students don't get to participate in other aspects of the mathematicians' work. Yvette Solomon describes a discussion of first-year undergraduate students' personal epistemologies of mathematics and mathematics learning. In her 
interviews with 12 first year university students the students described themselves as "outside of the mathematics community. Their relationship with the lecturers required them to engage only with mathematics as already created rather than with the disciplinary process of creation and validation of knowledge, and their experience of missing explanations and exclusivity placed them on the periphery of the community". Drawing on Wenger's theories, Solomon emphasises the importance of the interface between an individual's beliefs about the discipline and their self-positioning within the community, be it school classroom or university lecture theatre. Within this theoretical framework, she considers students' epistemologies as central to an analysis of the nature of undergraduate learning and the shifts that are required in moving from pre-university to university mathematics.

According to De Corte et al. the overall picture of students' beliefs of mathematics include:

- Mathematics is associated with certainty.

- Doing mathematics corresponds to following rules prescribed by the teacher.

- Knowing mathematics means being able to recall and use the correct rule.

- Mathematics becomes true when it is approved by the authority of the teacher.

- Mathematics problems have one and only one right answer.

- Mathematics is a solitary activity, done by individuals in isolation.

The following paragraph explains why maths support centres are seen as very valuable resources to provide opportunities for students to participate in communities of mathematical practice and to develop appropriate mathematical identities and epistemologies.

\section{The role of Maths Support Centres in Communities of Mathematical Practice}

It is no doubt a challenge to provide opportunities for incoming students to participate in communities of mathematical practice and to negotiate their beliefs of mathematics. However, I argue that maths support centres do provide such opportunities. Students are encouraged to explore mathematics, somewhat in a similar way as research mathematicians do their work.

For example in these centres students

- Talk, read and validate mathematics,

- Discuss different approaches,

- Use mathematical symbols and artefacts,

- Teach and learn from each other, and

- Share experience with 'oldtimers', i.e. PhD students or lecturers.

As the manager of the maths support centre at the National University of Ireland (NUI), Galway, I have observed the development of several students from first year at university to graduation and beyond who were very regular visitors of our centre. Some of them told me that the centre and people from the community played a major role in their development and decision for professional 
progression after graduating. It was the everyday exploring of mathematics within the community which inspired them to apply for $\mathrm{PhD}$ programmes in mathematics. This phenomenon is an important aspect of our support centre and the theory described above may provide a framework to describe and explain it.

While the evidence for this phenomenon is anecdotal at this stage, I will describe my subjective observations. The MSOR conference in Glasgow allowed me to discuss these ideas with colleagues to get an insight if they share these views and experiences and consider further investigations worthwhile.

The maths support centre at NUI Galway is on the ground floor of the building where all mathematics and statistics lecturers of the 'School of Maths' have their offices. The maths support centre is located between the School's office, a meeting room and the staff room and therefore even locally plays a central part in our community.

Over the years we observe students who come in during their first year at university, often not confident about their mathematical competence, looking for procedures or 'recipes' to approach their homework questions. Some of these students become regular visitors and often already after a few months significant changes of behaviour and attitudes towards approaching mathematics can be noted. Very quickly these students start working together and it is not unusual for tutors to hear "We may get back to you later, but would like to think about this ourselves first". Often finding a solution to a mathematical problem is not sufficient for them anymore, they start considering alternative methods. So changes to the above described beliefs about mathematics can often be identified after only a few months of visiting the support centre. There are several white boards in the support centre. Some of the students like to use these to explore their own ideas or to work in small groups. Several students who started studying mathematics with poor confidence, became almost daily visitors and applied for a PhD in mathematics after finishing their degrees. These students claim that they 'basically lived in' the maths support centre. Over the years they became more and more part of the community, took part at workshops and volunteered to help out in their final year. They got to know all our research students very well.

Of course, not all of our visitors aim to become mathematics researchers, and many students mostly use the maths support centre to get help with the requirements to pass their mathematics or statistics modules, however each year a significant number of students use the centre as an ideal environment to explore mathematics and develop problem solving skills.

In my view providing opportunities for participation in mathematical communities of practice and for development of mathematical identities are crucial aspects of maths support centres which may be underestimated. Here I have described my own subjective observations of a phenomenon. In case colleagues from maths support centres in other institutions share these views, a joint project to investigate further might be worth consideration.

\section{References}

De Corte, E. Op't Eynde, P. Depaepe, F and Verschaffen, L., 2010. The reflexive relation between students' mathematics related beliefs and the mathematics classroom culture. In L. Bendixen \& F. Feucht (Eds.), Personal Epistemology in the Classroom: Theory, Research, and Implications for Practice (pp. 292-327). Cambridge: Cambridge University Press. doi:10.1017/CBO9780511691904.010 
Hemmi, K. 2006. Approaching Proof in a Community of Mathematical Practice. Doctoral Thesis, Stockholm University.

Lave, J. and Wenger, E., 1991. Situated Learning: Legitimate peripheral participation. Vol. 521423740. Cambridge University Press, Cambridge.

Solomon, Y., 2006. Deficit or difference? The role of students' epistemologies of mathematics in their interactions with proof. Educational Studies in Mathematics 61(373). https://doi.org/10.1007/s10649006-6927-1. Kluwer Academic Publishers.

Wenger, E., 1998. Communities of Practice: learning, meaning and identity. Cambridge University Press, Cambridge. 